\title{
Dreaming during the COVID-19 lockdown: a comparison of Italian adolescents and adults
}

\author{
Massimiliano Sommantico, ${ }^{1}$ Ilaria Iorio, ${ }^{2}$ Marina Lacatena, ${ }^{2}$ Santa Parrello ${ }^{2}$ \\ ${ }^{1}$ Dynamic Psychology Laboratory, Department of Humanities, University of Naples Federico II; ${ }^{2}$ Department of Humanities, University \\ of Naples Federico II, Naples, Italy
}

\begin{abstract}
Based on the continuity hypothesis of dreaming, we have studied the effects of lockdown measures on Italian adolescents' and adults' dreams during the first wave of the coronavirus disease 2019 (COVID-19) pandemic. A sample of 475 subjects (73.9\% women; $48.4 \%$ adolescents; ages $12-70$ years, $\mathrm{M}=25.10, \mathrm{SD}=12.2$ ) was

Correspondence: Massimiliano Sommantico, Dynamic Psychology Laboratory, Department of Humanities, University of Naples Federico II, via Porta di Massa 1, 80133 Naples, Italy.

Tel.: +39.081.253603.

E-mail: sommanti@unina.it

Contributions: M.S., I.I., and S.P. substantially contributed to the conception of the study, the analysis and interpretation of data, as well as to drafting the manuscript and revising it critically. M.L. substantially contributed to the acquisition of data and to drafting the manuscript. All authors approved the final version of the manuscript to be published and agreed to be accountable for all aspects of the work in ensuring that questions related to the accuracy or integrity of any part of the work are appropriately investigated and resolved.

Conflict of interests: the authors declare no potential conflict of interests.

Availability of data and material: data and materials are available under request.

Ethical approval and consent to participate: the study complied with the American Psychological Association (APA) ethical standards in the treatment of human research participants and con-

recruited via the Internet between April 17, 2020 and May 18, 2020. Participants were asked to provide socio-demographic data, as well as to report their Most Recent Dream. Results indicated that adults' dreams were the longest, as well as characterized by higher emotional intensity, predominantly negative emotions, and a higher presence of sensory impressions. Furthermore, results indicated that the participants, especially adolescents, who were most directly affected by the COVID-19 pandemic reported the strongest effects on their dreams. Results also indicated that women recall dreams more often than men, in addition to reporting higher emotional intensity, predominantly negative emotions, and a higher presence of sensory impressions. Finally, results of the Thematic Analysis of Elementary Contexts showed that adults' dreams seem to be centered, above all, on both pleasant memories linked to experiences that are now forbidden (i.e., traveling, meeting friends) as well as on nightmares, while adolescents' dreams focused on relationships with others. Finally, both adults and adolescents reported dreams related to the experience of home confinement, which they described in terms of the negative emotions they experienced. In sum, the findings of this study indicate that the COVID-19 lockdown measures, understood as a contextual and traumatic event, significantly affect people's oneiric lives, regardless of age.
\end{abstract} formed to the provisions of the 1964 Helsinki declaration and its later amendments. Furthermore, the study was approved by the Ethical Committee of Psychological Research of the Department of Humanities of the University of Naples Federico II (protocol n. 14/2020). Informed consent to participate was obtained from all individual participants included in the study.

Citation: Sommantico, M., Iorio, I., Lacatena, M., \& Parrello, S. (2021). Dreaming during the COVID-19 lockdown: a comparison of Italian adolescents and adults. Research in Psychotherapy: Psychopathology, Process and Outcome, 24(2), 212-223. doi: 10.4081/ripppo.2021.536

Received for publication: 12 March 2021.

Revision received: 3 July 2021.

Accepted for publication: 3 July 2021.

This work is licensed under a Creative Commons Attribution NonCommercial 4.0 License (CC BY-NC 4.0).

${ }^{\circ}$ Copyright: the Author(s), 2021

Licensee PAGEPress, Italy

Research in Psychotherapy:

Psychopathology, Process and Outcome 2021; 24:212-223

doi:10.4081/ripppo.2021.536
Key words: Dreams; COVID-19 pandemic; lockdown; traumatic events; nightmares.

\section{Introduction}

The coronavirus disease 2019 (COVID-19), a respiratory disease causing the severe acute respiratory syndrome-related coronavirus 2 (SARS-CoV-2), was identified in January 2020 by the Chinese Center for Disease Control and Prevention and, in March 2020, was declared a global pandemic by the World Health Organization. Since then, data regarding infections and deaths all around the world have been steadily increasing, leading governments to adopt strong countermeasures, such as quarantine-isolation, in order to reduce the spread of contagion. The prohibition of all forms of gathering in public places, the suspension of teaching activities of any order and kind, the closure of museums, the suspension 
of commercial retail activities (except for the sale of food and basic necessities), the suspension of all catering activities (including bars, pubs, etc.), the suspension of activities relating to personal services (including hairdressers, barbers, beauticians, wellness centers, etc.), and the maximized use of remote work, have all resulted in a drastic form of social isolation which historically has never been seen before.

Italy is one of the European countries most affected by the pandemic, with $2,597,446$ confirmed cases and 90,241 deaths (at the time of writing). The first Italian and international studies investigating the psychological consequences of the COVID-19 pandemic have shown that quarantine-isolation measures related to the COVID-19 pandemic are associated with increased individual and relational psychological distress, anxiety, and depression (e.g., Sommantico, 2010; Sommantico et al., 2015; Benke, Autenrieth, Asselmann, \& Pané-Farré, 2020; Cellini et al., 2020; Faustino et al., 2020; Gullo, Misici, Teti, Liuzzi, \& Chiara, 2020; Huang \& Zhao, 2020; Lebow, 2020; Parola et al., 2020; Prime, Wade, \& Browne, 2020). Furthermore, several studies (e.g., Casagrande et al., 2020; Franceschini et al., 2020; Gorgoni et al., 2021; Sher, 2020; Xiao, Zhang, \& Kong, 2020) have especially focused on sleep disorders, or poor sleep quality, as related to the consequences of quarantine-isolation, which were, among others, remote work and changes to sleep schedules, as well as lack of rest and regular physical exercise.

It is, therefore, not excessive to define this period as traumatic, during which mental health services have recorded both a worsening of psychological symptoms of various individuals with prior struggles, and a generalized spread of anxiety and depression (e.g., Knight, 2020; Mazza et al., 2020; Rossi et al., 2020; Zandifar \& Badrfam, 2020; Wang, Zhou, \& Zong, 2020; Zurlo, Cattaneo della Volta, \& Vallone, 2020).

Based on the continuity hypothesis of dreaming, which states that dream content reflects waking life (e.g., Domhoff, 1996; Schredl, 2006), it is possible to think that the subjective impact of traumatic and/or catastrophic life events, such as the COVID-19 pandemic, can be reflected in the dream content of people subject to quarantine-isolation measures. Indeed, findings in the literature of dream studies, as related to war conflicts, traumatic and/or catastrophic events (e.g., Barrett, 2001; Hartman \& Basile, 2003; Rosen et al., 1991; Schredl, 2006), and waking concerns or threats (e.g., Bradshaw et al., 2016; Davidson \& Lynch, 2012; Hartmann, 2011; Mathes \& Schredl, 2016), as well as recent studies on populations subject to the restrictive measures related to the COVID-19 pandemic (e.g., Barrett, 2020; Iorio et al., 2020; Parrello et al., 2020; McKay \& DeCicco, 2020; Pesonen et al., 2020; Scarpelli et al., 2021; Schredl \& Bulkeley, 2020), show that these events have a strong impact on dreams due to their emotional salience, which thereby influence dream content.
In particular, it has emerged that participants who experience COVID-19 more directly, through close relations to people who have been affected by or who have died of COVID-19, reported higher emotional intensity and sensory impressions (Barret, 2020; Iorio et al., 2020; Parrello et al., 2020; Schredl \& Bulkeley, 2020). Furthermore, during the early phase of the pandemic, dream imagery was characterized by a high presence of virus-related themes (McKay \& DeCicco, 2020; Pesonen et al., 2020), such as concerns and anxieties related to contagion.

In the same vein, according to psychoanalytic thought (Adams-Silvan \& Silvan, 1990; Sommantico, 2016; Sommantico, 2018; Sommantico et al., 2017), dreams can be interpreted not only as attempts at fulfilling repressed wishes, as highlighted by the early work of Freud (1900), but also as ways to retrospectively master and transform a waking life traumatic event (Freud, 1915-17). Following this line of thinking, it seems that significant events in waking life can be associated with specific experiences of dreaming, especially with dreamt emotions and threats.

In accordance with this theoretical framework, we have hypothesized that the dreams of people living with quarantine-isolation measures related to the COVID-19 pandemic are mainly realistic, and are characterized by strong negative emotional intensity, a strong emotional tone, and the presence of sensory impressions (Hypothesis 1).

Furthermore, we are interested in understanding if, and how, the dangers of infection and death, and the quarantine-isolation measures, were represented in dreams. We then hypothesized that participants' most recent dreams would represent the places where quarantine-isolation is lived out, as well as that especially negative emotions, such as fear and anxiety, would emerge, related to dangerous and/or frustrating situations (Hypothesis 2).

Finally, based on previous dream research (e.g., Nielsen et al., 2000; Schredl, 2002; Schredl \& Reinhard, 2008; Settineri et al., 2019), as well as recent studies on dreaming at the time of COVID-19 (e.g., Barrett, 2020; Iorio et al., 2020; Parrello et al., 2020; McKay \& DeCicco, 2020; Pesonen et al., 2020; Scarpelli et al., 2021; Schredl \& Bulkeley, 2020 ), we hypothesized that women would recall their dreams more often than men, as well as evaluate them as more emotionally intense (Hypothesis 3 ).

\section{Materials and Methods}

\section{Participants}

Participants were recruited in Italy via the Internet between April 17, 2020 and May 18, 2020, according to the following criteria: at least 18 years of age and compliant with the quarantine measures. All data were collected through self-report questionnaires, using an Internet-based survey (Hewson, Vogel, \& Laurent, 2016). Participation in the study was voluntary, anonymous, and unpaid. All participants included in the study gave consent to partic- 
ipate on the first page of the survey. The informed consent included detailed information about the aims and procedures of the study, confidentiality, and the anonymity of the responses. After signing the informed consent, participants first completed a socio-demographic questionnaire. Participants were also asked to report their Most Recent Dream (MRD). Means across each participant's reported dreams were calculated for word count. Dream reports were arranged and scored on the dream rating scales by three independent judges.

The study complied with the American Psychological Association (APA) ethical standards in the treatment of human research participants and conformed to the provisions of the 1964 Helsinki Declaration and its later amendments. Furthermore, the study was approved by the Ethical Committee of Psychological Research of the Department of Humanities of the University of Naples Federico II (protocol no. 14/2020).

There were 475 respondents ( $73.9 \%$ women; $48.4 \%$ adolescents; ages $12-70$ years, $\mathrm{M}=25.10, \mathrm{SD}=12.2$ ). Participants living within a big city or its suburbs were $51.4 \%$. The majority of participants $(86.7 \%)$ lived with family during the quarantine period (13.3\% in a couple, $4.8 \%$ with friends, and $3.4 \%$ alone). The mean number of people cohabitating during the quarantine period was 3.8 $(\mathrm{SD}=1.4)$. The majority of participants $(51.6 \%)$ lived in a house that was between 80 and 140 square meters, with their own room available (75.8\%). The sample had a high level of education, with $61.9 \%$ of the participants having completed secondary school, and $31.6 \%$ having completed a university degree or a post-university degree. Participants who knew someone infected by COVID-19 were $36.8 \%$, and participants who knew someone who died of COVID-19 were $22.1 \%$.

\section{Measures}

Socio-Demographic Questionnaire. Respondents provided socio-demographic data [e.g., age, gender, residence type (ranging from stand-alone homes to urban downtowns), level of education] via a basic socio-demographic questionnaire. Respondents were also asked to report information about their quarantine (e.g., number of people cohabitating, dimensions of their house), and whether they knew people affected by or who have died of COVID-19.

Dream Questionnaire. Dream frequency recall was measured on a 7 -point scale $(0=$ never; $1=$ less than once a month; $2=$ about once a month; $3=$ about two to three times a month; $4=$ about once a week; $5=$ several times a week; 6=almost every morning) (Schredl, 2002, 2010a; Settineri et al., 2019). Following the indications of Schredl (2002, 2010a), participants were also asked to self-rate the emotional intensity of their dreams (on a 5-point scale, ranging from $1=$ not intense to $5=$ =very intense), and the overall emotional tone of their dreams (on a 3-point scale: $-1=$ predominantly negative; $0=$ balanced, $+1=$ predominantly positive).
Most Recent Dream (MRD). Regarding the MRD (Hall \& Van de Castle, 1966; Domhoff, 1996, 2003), we asked participants to indicate: i) whether the dream occurred last night, last week, or last month; ii) the date the dream occurred; and iii) what time of day the dream was recalled. Participants were also asked to: i) describe the dream as precisely and as fully as they could remember it; ii) describe the setting of the dream, whether it was familiar or not; iii) describe the people and their sex, age, and relationship to the dreamer; iv) describe any animals or objects that appeared in the dream; e) describe their feelings during the dream and whether they were pleasant or unpleasant; f) explain exactly what happened during the dream to themselves and the other characters. Participants were also asked to self-rate their dream (Domhoff, 1996; Schredl, 2002, 2010a) regarding: i) the intensity of the positive emotions of the dream (on a 4-point scale, ranging from $0=$ no emotions to $3=$ intense emotions); ii) the intensity of the negative emotions of the dream (on a 4-point scale, ranging from $0=$ no emotions to $3=$ intense emotions); iii) the realism/bizarreness of the dream (on a 4-point scale, ranging from $0=$ realistic dream to $3=$ bizarre dream); and iv) the presence of sensory impressions in the dream (on a 4-point scale, ranging from $0=$ no sensory impressions to $3=$ strong sensory impressions).

\section{Data analyses}

Survey data were then entered into SPSS 26.0 (IBM Corp., 2019) for the quantitative analyses, and T-LAB (Lancia, 2004) for the quali-quantitative analyses. Data were checked/verified by project staff for accuracy, in order to preserve the meaning-making process carried out by the researcher.

Descriptive analyses were conducted to outline the sociodemographic characteristics of the sample, as well as the COVID-19 related variables, by considering the following features: age, gender, residence type (ranging from stand-alone homes to urban downtowns), level of education, number of people cohabitating during the quarantine-isolation, dimensions of the house, relationship to people affected by COVID-19, and relationship to people who have died of COVID-19. The chi-squared test with Bonferroni adjusted post hoc tests was used to compare the two distributions (adult subsample versus adolescent subsample, and male subsample versus female subsample) of dream recall frequency (P-value $<0.05$ ), and t-test was used to verify the differences between the subject groups (P-value $<0.05$ ). Ordinal logistic regression models were used for ordinal outcome variables (i.e., dream recall frequency, relationship to people affected by or who have died of COVID-19) (P-value $<0.05$ ).

Following the international recommendations on dream content scales (e.g., Hoffman, 2013; Schredl, 2002, 2010a; Schredl \& Doll, 1998), the rating scales used for the quantitative analyses were the same as those utilized for the MRDs. This was done in order to compare partic- 
ipants' self-ratings and judges' ratings of the following: i) the intensity of the positive emotions; ii) the intensity of the negative emotions; iii) realism/bizarreness; and iv) the presence of sensory impressions. All scales used the same format as the self-rating scales in the dream questionnaire. The interrater reliability coefficients (Spearman rank correlations) for these scales were high and range from 0.67 (realism/bizarreness) to 0.82 (negative emotions).

The MRDs' text corpora (adolescents' and adults' dreams) went through a stemming process (automatic lemmatization), and a Thematic Analysis of Elementary Contexts was performed. The text was partitioned into elementary context units, each being approximately the length of a sentence. The units were then classified according to the distributions of words in terms of co-occurrences. Cluster analysis was carried out by an unsupervised ascendant hierarchical method (Bisecting K-Means Algorithm). The co-occurrence of semantic features characterizes this analysis. Each cluster consisted of a set of keywords (specific vocabulary), which were ranked according to the decreasing value of chi-square, and of a selection of elementary contexts (max. 20 for each cluster), which were sorted by the weighted descending order of characteristic words. A label was then assigned to each of them.

\section{Results}

\section{Dream recall frequency and content measures}

According to Schredl's recommendations (2002), participants were divided into three categories: i) low recallers $=$ never to about once a month, $13.1 \%$; ii) medium recallers=about 2-3 times a month to about once a week, $45.3 \%$; and iii) high recallers $=$ several times a week to almost every morning, $41.7 \%$. Regarding emotional intensity, participants reported high emotional intensity $(\mathrm{M}=2.8 ; \mathrm{SD}=1.1)$. Finally, regarding emotional tone, participants reported a mostly balanced emotional tone in their dreams $(\mathrm{M}=-0.2 ; \mathrm{SD}=0.6)$. Data regarding adult and adolescent subsamples are presented in Table 1.

Statistical comparisons via chi-squared test with Bon- ferroni adjusted post hoc tests showed that the distribution of dream recall frequency in the adult subsample differs significantly from that of the adolescent subsample: $\chi^{2}(2)=10.055, P=0.007$. In particular, we observe a significantly higher percentage of low recallers in the adult subsample (Bonferroni adjusted $a$ levels of 0.0028 per test $0.05 / 6$ ). There was no significant difference, in the two subsamples, regarding the percentage of medium and high recallers.

Statistical comparisons via chi-squared test with Bonferroni adjusted post hoc tests showed that the distribution of dream recall frequency in the male subsample differs significantly from that of the female subsample: $\chi^{2}(2)=8.03$, $\mathrm{P}=0.018$. In particular, in the female subsample, we observe a significantly higher percentage of high recallers (Bonferroni adjusted $a$ levels of .0012 per test .05/6).

Regarding gender, t-test showed significant differences. Indeed, female participants $(\mathrm{M}=2.91, \mathrm{SD}=0.97)$ reported a significantly higher emotional intensity of their dreams when compared to male participants $(\mathrm{M}=2.60, \mathrm{SD}=1.01)$ $(\mathrm{M}=-0.31,95 \%$ CI $[-0.51,-0.10], \mathrm{t}(473)=-2.977$, $\mathrm{P}=0.003, \mathrm{~d}=0.31$ ). Furthermore, $t$-test showed significant differences between adult and adolescent subsamples in terms of dreams' emotional tone. Indeed, adult participants $(\mathrm{M}=-0.22, \mathrm{SD}=0.59)$ reported a significantly higher negative emotional tone to their dreams than adolescent participants $(\mathrm{M}=-0.09, \mathrm{SD}=0.69)(\mathrm{M}=0.13,95 \%$ CI $[0.01$, 0.24], $\mathrm{t}(473)=2.123, \mathrm{P}=0.034, \mathrm{~d}=0.21)$.

Based on previous results, regressions analyses were for comparing the dependent ordinal variables (dream recall frequency, emotional intensity, and emotional tone) to gender, word count, relationship to people affected by COVID-19, and relationship to people who have died of COVID-19 as independent variables, with age and level of education controlled. Results are shown in Table 2.

Regarding the adolescent subsample, significant causal relationships were found between dream recall frequency, emotional intensity, and emotional tone, thus indicating that participants who reported longer dreams were higher recallers. They also reported higher emotional intensity and a predominantly negative emotional tone to their dreams. Furthermore, participants who knew people

Table 1. Dream recall frequency and content.

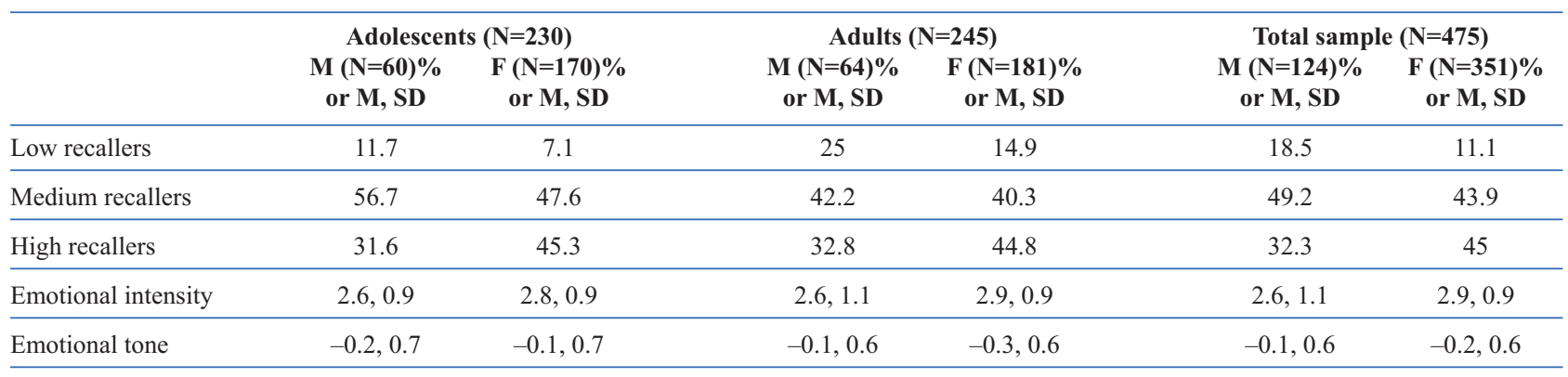

M, males; F, females. 
affected by COVID-19 reported higher emotional intensity and a predominantly negative emotional tone to their dreams. Finally, participants who knew people who have died of COVID-19 reported a higher emotional intensity of their dreams.

Regarding the adult subsample, significant causal relationships were found between dream recall frequency, emotional intensity, and emotional tone, thus indicating that female participants, as well as participants who reported longer dreams, are higher recallers. They also reported higher emotional intensity and a predominantly negative emotional tone to their dreams. Furthermore, participants who knew people affected by COVID-19 were higher recallers than those who did not.

\section{Most recent dream quali-quantitative analysis}

In reporting their MRDs, the majority of participants $(54.9 \%)$ indicated that the dream occurred during the last week (23.6\% last night, and $17.7 \%$ last month), and that they mainly recalled the dream during the morning $(81.1 \%)$. The mean dream length was 100.1 words $(\mathrm{SD}=105.8)$.

Regarding emotional intensity, participants reported medium positive emotions $(\mathrm{M}=1.5 ; \mathrm{SD}=1.1)$ and high negative emotions $(\mathrm{M}=1.7 ; \quad \mathrm{SD}=1.2)$. Regarding realism/bizarreness, participants reported medium realism $(\mathrm{M}=1.4 ; \mathrm{SD}=1.0)$. Finally, regarding the presence of sensory impressions, participants reported a high presence of sensory impressions ( $\mathrm{M}=1.8 ; \mathrm{SD}=1.0)$ (Table 3).

Table 2. Regression analyses for dream variables.

\begin{tabular}{|c|c|c|c|c|c|c|c|c|c|c|c|c|}
\hline \multirow[t]{2}{*}{$\begin{array}{l}\text { Adolescents' subsample } \\
(\mathbf{N}=\mathbf{2 3 0})\end{array}$} & \multicolumn{3}{|c|}{ Effect of gender } & \multicolumn{3}{|c|}{ Effect of word count } & \multicolumn{3}{|c|}{$\begin{array}{l}\text { Effect of knowing } \\
\text { a COVID-19 case }\end{array}$} & \multicolumn{3}{|c|}{$\begin{array}{l}\text { Effect of knowing } \\
\text { a COVID-19 death }\end{array}$} \\
\hline & $\beta$ & $\chi^{2 / t}$ & $\mathbf{P}$ & $\beta$ & $\chi^{2 / t}$ & $\mathbf{P}$ & $\beta$ & $\chi^{2 / t}$ & $\mathbf{P}$ & $\beta$ & $\chi^{2 / t}$ & $\mathbf{P}$ \\
\hline Dream recall frequency & 0.017 & 3.85 & 0.050 & 0.579 & 198.89 & $0.001 *$ & 0.000 & 0.04 & 0.841 & 0.000 & 0.01 & 0.937 \\
\hline Emotional intensity & 0.009 & 2.10 & 0.147 & 0.786 & 354.43 & $0.001 *$ & 0.040 & 9.29 & $0.002 *$ & 0.026 & 5.97 & $0.015^{*}$ \\
\hline Overall emotional tone & 0.004 & 0.98 & 0.320 & 0.653 & 243.61 & $0.001 *$ & 0.041 & 9.68 & $0.002 *$ & 0.013 & 3.03 & 0.082 \\
\hline \multirow[t]{2}{*}{$\begin{array}{l}\text { Adults' subsample } \\
(\mathrm{N}=\mathbf{2 4 5})\end{array}$} & \multicolumn{3}{|c|}{ Effect of gender } & \multicolumn{3}{|c|}{ Effect of word count } & \multicolumn{3}{|c|}{$\begin{array}{l}\text { Effect of knowing } \\
\text { a COVID-19 case }\end{array}$} & \multicolumn{3}{|c|}{$\begin{array}{l}\text { Effect of knowing } \\
\text { a COVID-19 death }\end{array}$} \\
\hline & $\beta$ & $\chi^{2} / \mathbf{t}$ & $\mathbf{P}$ & $\beta$ & $\chi^{2 / t}$ & $\mathbf{P}$ & $\beta$ & $\chi^{2} / \mathbf{t}$ & $\mathbf{P}$ & $\boldsymbol{\beta}$ & $\chi^{2} / \mathbf{t}$ & $\mathbf{P}$ \\
\hline Dream recall frequency & 0.017 & 4.15 & $0.042 *$ & 0.608 & 229.43 & $0.001 *$ & 0.019 & 4.71 & $0.030^{*}$ & 0.006 & 1.38 & 0.240 \\
\hline Emotional intensity & 0.025 & 6.24 & $0.013 *$ & 0.631 & 244.34 & $0.001 *$ & 0.001 & 0.19 & 0.661 & 0.000 & 0.00 & 0.962 \\
\hline Overall emotional tone & 0.025 & 6.16 & $0.013^{*}$ & 0.579 & 212.17 & $0.001 *$ & 0.004 & 0.94 & 0.332 & 0.002 & 0.45 & 0.503 \\
\hline \multicolumn{3}{|c|}{$\begin{array}{l}\text { Total sample Effect of gender } \\
(\mathrm{N}=475)\end{array}$} & \multicolumn{3}{|c|}{ Effect of word count } & \multicolumn{3}{|c|}{$\begin{array}{l}\text { Effect of knowing } \\
\text { a COVID-19 case }\end{array}$} & \multicolumn{3}{|c|}{$\begin{array}{l}\text { Effect of knowing } \\
\text { a COVID-19 death }\end{array}$} & \\
\hline & $\boldsymbol{\beta}$ & $\chi^{2} / \mathbf{t}$ & $\mathbf{P}$ & $\boldsymbol{\beta}$ & $\chi^{2} / \mathbf{t}$ & $\mathbf{P}$ & $\beta$ & $\chi^{2} / \mathrm{t}$ & $\mathbf{P}$ & $\boldsymbol{\beta}$ & $\chi^{2} / \mathbf{t}$ & $\mathbf{P}$ \\
\hline Dream recall frequency & 0.017 & 7.91 & $0.005^{*}$ & 0.425 & 263.08 & $0.003 *$ & 0.005 & 2.29 & 0.130 & 0.002 & 0.95 & 0.330 \\
\hline Emotional intensity & 0.017 & 8.15 & $0.004 *$ & 0.506 & 335.14 & $0.001 *$ & 0.007 & 3.37 & 0.067 & 0.005 & 2.55 & 0.111 \\
\hline Overall emotional tone & 0.002 & 0.82 & 0.364 & 0.469 & 300.72 & $0.001 *$ & 0.018 & 8.71 & $0.003 *$ & 0.006 & 2.72 & 0.099 \\
\hline
\end{tabular}

$\beta$, standardized estimates; ${ }^{*} \mathrm{P}<0.05$.

Table 3. Most recent dreams' content.

\begin{tabular}{|c|c|c|c|c|c|c|}
\hline & \multicolumn{2}{|c|}{ Adolescents $(\mathrm{N}=\mathbf{2 3 0})$} & \multicolumn{2}{|c|}{ Adults $(N=245)$} & \multicolumn{2}{|c|}{ Total sample $(\mathrm{N}=\mathbf{4 7 5})$} \\
\hline & $\begin{array}{c}M(N=60) \% \\
\text { or } M, S D\end{array}$ & $\begin{array}{c}\mathrm{F}(\mathrm{N}=170) \% \\
\text { or } \mathrm{M}, \mathrm{SD}\end{array}$ & $\begin{array}{c}M(N=64) \% \\
\text { or } M, S D\end{array}$ & $\begin{array}{c}\text { F }(\mathrm{N}=181) \% \\
\text { or } M, S D\end{array}$ & $\begin{array}{c}M(N=124) \% \\
\text { or } M, S D\end{array}$ & $\begin{array}{c}\mathrm{F}(\mathrm{N}=351) \% \\
\text { or } \mathrm{M}, \mathrm{SD}\end{array}$ \\
\hline Dream length & $77.3,77.9$ & $91.9,76.9$ & $90.4,110.9$ & $118.7,130.3$ & $84.1,96.2$ & $105.8,108.5$ \\
\hline Last night & 18.3 & 23 & 23.5 & 23.2 & 22.6 & 23.9 \\
\hline Last week & 41.7 & 53.5 & 53.1 & 56.9 & 48.4 & 57.3 \\
\hline Last month & 26.7 & 17.6 & 15.6 & 12.7 & 22.6 & 16 \\
\hline Past month & 13.3 & 5.9 & 7.8 & 7.2 & 6.4 & 2.8 \\
\hline Positive emotions & $1.6,1.1$ & $1.3,1.2$ & $1.8,0.9$ & $1.4,1.1$ & $1.7,0.9$ & $1.4,1.2$ \\
\hline Negative emotions & $1.2,1.1$ & $1.7,1.3$ & $1.6,1.1$ & $2.0,1.1$ & $1.4,1.1$ & $1.8,1.2$ \\
\hline Realism/bizarreness & $1.4,1.2$ & $1.4,1.0$ & $1.5,1.0$ & $1.5,0.9$ & $1.5,1.1$ & $1.5,1.0$ \\
\hline Sensory impressions & $1.5,1.0$ & $1.7,0.9$ & $1.7,0.9$ & $2.0,0.9$ & $1.6,1.0$ & $1.8,0.9$ \\
\hline
\end{tabular}

M, males; F, females. 
Regarding gender, t-test showed significant differences. Indeed, female participants reported significantly longer MRDs $(\mathrm{M}=105.77, \mathrm{SD}=108.50)(\mathrm{M}=-21.79,95 \%$ CI $[-43.33,-0.05], \mathrm{t}(473)=-1.970, \mathrm{P}=0.049, \mathrm{~d}=0.09)$, significantly lower positive emotions $(\mathrm{M}=1.38, \mathrm{SD}=1.16)$ $(\mathrm{M}=0.33,95 \%$ CI $[0.10,0.55], \mathrm{t}(473)=2.785, \mathrm{P}=0.006$, $\mathrm{d}=0.31)$, significantly higher negative emotions $(\mathrm{M}=1.83$, $\mathrm{SD}=1.19)(\mathrm{M}=-0.40,95 \%$ CI $[-0.64,-0.16], \mathrm{t}(473)=-$ $3.269, \mathrm{P}=0.001, \mathrm{~d}=0.29)$, and a significantly higher presence of sensory impressions $(\mathrm{M}=1.87, \mathrm{SD}=0.94)(\mathrm{M}=$ $-0.28,95 \%$ CI $[-0.47,-0.08], \mathrm{t}(473)=-2.758, \mathrm{P}=0.006$, $\mathrm{d}=0.30)$ in their MRDs than male participants $(\mathrm{M}=84.07$, $\mathrm{SD}=96.20 ; \quad \mathrm{M}=1.71, \quad \mathrm{SD}=0.99 ; \quad \mathrm{M}=1.43, \quad \mathrm{SD}=1.13$; $\mathrm{M}=1.60, \mathrm{SD}=1.01)$. Furthermore, t-test showed significant differences in dream length between adult and adolescent subsamples. Indeed, adult participants $(\mathrm{M}=111.32$, $\mathrm{SD}=125.91)$ reported significantly longer MRDs than adolescent participants $(\mathrm{M}=88.16, \mathrm{SD}=77.33)(\mathrm{M}=-$ $23.16,95 \%$ CI $[-42.14,-4.17], \mathrm{t}(473)=-2.397, \mathrm{P}=0.017$, $\mathrm{d}=0.20$ ). Finally, t-test showed significant differences in negative emotions and sensory impressions between the adult and adolescent subsamples. Indeed, adult participants reported significantly higher negative emotions $(\mathrm{M}=1.87, \mathrm{SD}=1.11)(\mathrm{M}=-0.29,95 \%$ CI $[-0.50,-0.08]$, $\mathrm{t}(473)=-2.689, \mathrm{P}=0.007, \mathrm{~d}=0.26)$ and a significantly higher presence of sensory impressions $(\mathrm{M}=1.93$, $\mathrm{SD}=0.94)(\mathrm{M}=-0.28,95 \% \mathrm{CI}[-0.45,-0.11], \mathrm{t}(473)=-$ 3.182, $\mathrm{P}=0.002, \mathrm{~d}=0.28)$ in their MRDs than adolescent participants $(\mathrm{M}=1.57, \mathrm{SD}=1.25 ; \mathrm{M}=1.66, \mathrm{SD}=0.96)$.
Results of zero-order correlations between participants' self-ratings and judges' mean ratings showed small to large significant positive associations, with $r$ values (P£0.001) ranging from 0.21 to 0.68 .

Based on previous results, regressions analyses were run for comparing the dependent ordinal variables (positive emotions, negative emotions, realism/bizarreness, and sensory impressions) to gender and the COVID-19 variables (relationship to a COVID-19 case or death) as independent variables, with age and level of education controlled. Results are shown in Table 4.

Regarding the adolescent subsample, significant causal relationships were found between positive and negative motion, as well as with realism/bizarreness, thus indicating that female participants and participants having a relationship to a COVID-19 case or death reported higher negative emotions in their MRDs. Furthermore, participants with a relationship to a COVID-19 death also reported MRDs characterized by higher realism.

Regarding the adult subsample, significant causal relationships were found between positive and negative emotions, as well as with sensory impressions, thus indicating that male participants and participants having a relationship to a COVID-19 death reported higher positive emotions, while female participants reported higher negative emotions. Furthermore, participants with a relationship to a COVID-19 case or death reported higher negative emotions.

The adolescents' text corpus (235 MRDs) was char-

Table 4. Regression analyses for most recent dream variables.

\begin{tabular}{|c|c|c|c|c|c|c|c|c|c|}
\hline \multirow[t]{2}{*}{$\begin{array}{l}\text { Adolescents' subsample } \\
(\mathbf{N}=\mathbf{2 3 0})\end{array}$} & \multicolumn{3}{|c|}{ Effect of gender } & \multicolumn{3}{|c|}{$\begin{array}{l}\text { Effect of knowing } \\
\text { a COVID-19 case }\end{array}$} & \multicolumn{3}{|c|}{$\begin{array}{l}\text { Effect of knowing } \\
\text { a COVID-19 death }\end{array}$} \\
\hline & $\beta$ & $\chi^{2 / t}$ & $\mathbf{P}$ & $\boldsymbol{\beta}$ & $\chi^{2} / \mathbf{t}$ & $\mathbf{P}$ & $\boldsymbol{\beta}$ & $\chi^{2 / t}$ & $\mathbf{P}$ \\
\hline Positive emotions & 0.006 & 1.48 & 0.224 & 0.083 & 19.95 & $0.000 *$ & 0.133 & 32.89 & $0.000 *$ \\
\hline Negative emotions & 0.024 & 5.69 & $0.017^{*}$ & 0.116 & 28.23 & $0.000 *$ & 0.241 & 63.55 & $0.000 *$ \\
\hline Realism/bizarreness & 0.000 & 2.86 & 0.239 & 0.011 & 2.52 & 0.112 & 0.027 & 6.29 & $0.012 *$ \\
\hline Sensory impressions & 0.008 & 1.81 & 0.179 & 0.000 & 3.80 & 0.149 & 0.000 & 1.80 & 0.407 \\
\hline \multirow[t]{2}{*}{$\begin{array}{l}\text { Adults' subsample } \\
(\mathrm{N}=\mathbf{2 4 5})\end{array}$} & \multicolumn{3}{|c|}{ Effect of gender } & \multicolumn{3}{|c|}{$\begin{array}{l}\text { Effect of knowing } \\
\text { a COVID-19 case }\end{array}$} & \multicolumn{3}{|c|}{$\begin{array}{l}\text { Effect of knowing } \\
\text { a COVID-19 death }\end{array}$} \\
\hline & $\boldsymbol{\beta}$ & $\chi^{2 / t}$ & $\mathbf{P}$ & $\boldsymbol{\beta}$ & $\chi^{2} / \mathbf{t}$ & $\mathbf{P}$ & $\boldsymbol{\beta}$ & $\chi^{2 / t}$ & $\mathbf{P}$ \\
\hline Positive emotions & 0.029 & 7.09 & $0.008^{*}$ & 0.014 & 3.49 & 0.062 & 0.018 & 4.36 & $0.037^{*}$ \\
\hline Negative emotions & 0.022 & 5.54 & $0.019^{*}$ & 0.022 & 5.33 & $0.021 *$ & 0.058 & 14.59 & $0.000^{*}$ \\
\hline Realism/bizarreness & 0.000 & 2.49 & 0.284 & 0.003 & 0.67 & 0.413 & 0.003 & 0.85 & 0.357 \\
\hline Sensory impressions & 0.026 & 6.57 & $0.010^{*}$ & 0.001 & 0.25 & 0.615 & 0.004 & 1.09 & 0.296 \\
\hline \multirow[t]{2}{*}{$\begin{array}{l}\text { Total sample } \\
(\mathrm{N}=475)\end{array}$} & \multicolumn{3}{|c|}{ Effect of gender } & \multicolumn{3}{|c|}{$\begin{array}{l}\text { Effect of knowing } \\
\text { a COVID-19 case }\end{array}$} & \multicolumn{3}{|c|}{$\begin{array}{l}\text { Effect of knowing } \\
\text { a COVID-19 death }\end{array}$} \\
\hline & $\beta$ & $\chi^{2 / t}$ & $\mathbf{P}$ & $\beta$ & $\chi^{2} / \mathbf{t}$ & $\mathbf{P}$ & $\beta$ & $\chi^{2 / t}$ & $\mathbf{P}$ \\
\hline Positive emotions & 0.015 & 13.21 & $0.001 *$ & 0.041 & 20.12 & $0.000^{*}$ & 0.068 & 33.58 & $0.000^{*}$ \\
\hline Negative emotions & 0.023 & 4.10 & $0.001 *$ & 0.060 & 29.53 & $0.000^{*}$ & 0.135 & 68.93 & $0.000^{*}$ \\
\hline Realism/bizarreness & 0.000 & 3.48 & 0.175 & 0.006 & 2.96 & 0.687 & 0.014 & 6.51 & $0.011 *$ \\
\hline Sensory impressions & 0.016 & 7.52 & $0.006^{*}$ & 0.000 & 5.81 & 0.058 & 0.001 & 0.56 & 0.453 \\
\hline
\end{tabular}

$\beta$, standardized estimates; $* \mathrm{P}<0.05$. 
acterized by 20365 occurrences (of which 3679 are distinct forms; threshold=6). Within the corpus, 457 elementary context units (e.c.u.) were identified [of which 439 (96.1\%) were classified)], and 2430 lemmas. Analysis highlighted 4 clusters (Table 5).

Cluster 1: Home confinement: life from the balcony, comprised of 65 e.c.u. [of a total of 439 (14.8\%)]. Specific vocabulary: balcony, live, walking, parent, beautiful, child, garden, driveway, see, animal, leave, thought, pleasant, sad, worry. Examples of e.c.u.: 'After we saw the scene we walked onto the balcony because it was no longer possible to enter the house, even through the window. Then I saw him with all the blood. After a while, the window opened, and we were able to enter.' 'Anyway, later I showed him the street and told him how much I love the street where I live, because it is sparsely populated but has a beautiful view. Then we went to the other balcony because my best friend lives in the building next door, and we spent the rest of the evening chatting on the balcony with my best friend, who was also looking out of her window.'

Cluster 2: School: Danger and collapse of borders, comprised of 117 e.c.u. [of a total of 439 (26.7\%)]. Specific vocabulary: we, professor, escape, door, window, open, become, friend, earth, best, move, arrive, stay, policeman, shoot, our. Examples of e.c.u.: 'I was at school with my friends. The teacher told us that we had to stay very distant from each other due to the danger of contagion, but the classroom was too small, and an atmosphere of tension was created that kept growing. At one point the teacher began to scream. She kept telling us we were too close and that it was dangerous. The more she screamed, the more scared we were.' 'I was with my class at an airport, ready to leave for the trip. The ID card inspector was our Italian teacher, who had a crush on me. I was terrified because he had let all my mates pass except me, telling me that my card had expired and that I had to stay in the office for a week with him alone.' 'I am with various people at a rock concert in front of my school. At a certain point, a storm comes, and all the people take shelter in the school. Shortly after, we are all quarantined in the school, which becomes like a home for us, complete with showers in the corridors.'

Cluster 3: Friends and boyfriends: quarrels and betrayals, comprised of 134 e.c.u. [of a total of 439 $(30.5 \%)]$. Specific vocabulary: boy/girl, meeting, friend, side by side, real, beach, start, feeling, machine, find, seek, pleasure, try, ride, bar, pain, fight. Examples of e.c.u.: 'It is not very long. I dreamed of the boy I was getting to know who, while he was dating me, was also seeing others. We were out at a bar, and the place was familiar to me. I was with 5-6 other friends, both male and female, when suddenly I saw this guy with someone else. At that moment, I felt disappointed and teased: a bad feeling, let's say.' 'I was in my country and there were 4 guys who accompanied me on the street in the evening. I didn't know them. At some point one of them starts beating me and so do the others. I try to escape and ask for help from nearby people, but no one helps me. I try to flee to my house, but I discover that my parents have been kidnapped.'

Cluster 4: Death of family members, comprised of 123 e.c.u. [of a total of $439(28 \%)$ ]. Specific vocabulary: grandfather, uncle, memory, mom, period, death, tv, family, home, quarantine, die, cousin, call, minute, relative. Examples of e.c.u.: 'My grandmother passed away 3 years ago, and my grandfather was renovating the house just before he died. And I dreamed that I was crying a lot because I missed my grandmother. Suddenly I found myself in her old house, and then she appeared. She was cooking for the whole family, and all my relatives were there.' 'I dreamed of being at my house, with my grandmother and my mother. My grandmother's sister was dying, and my mother and grandmother were waiting for a call to find out if she was dead. In the evening, my mother left the cell phone in case the call came. I was in my room, and it was about 2 am.'

The adults' text corpus (245 MRDs) was characterized by 27322 occurrences (of which 4823 are distinct forms; threshold=6). Within the corpus 602 e.c.u. were identified [of which 591 (98.3\%) were classified)], and 3192 lemmas. Analysis highlighted 5 clusters (Table 6).

Cluster 1: Home confinement: sense of guilt and escape, comprised of 116 e.c.u. [of a total of 591 19.6\%]. Specific vocabulary: small, carry, run away, people, blame, cat, moment, lawn, detail, ground, worry, building, group, deep, return, open, fall, dog, COVID. Examples of e.c.u.: 'There was an earthquake and we all had to escape. I didn't feel the earth vibrate yet, but I knew it would come. But there was no solution and I had to bring my youngest son to safety, and I knew I would not make it. I was alone.' 'I went back to my parents' house to look after our dog while they were out of town. After receiving instructions not to open up for anyone, and that the dog was

Table 5. Cluster of adolescents' Most Recent Dreams.

\begin{tabular}{lccl}
\hline Cluster & No. & $\mathbf{\%}$ & Name \\
\hline 1 & 65 & 14.8 & Home confinement \\
\hline 2 & 117 & 26.7 & School \\
\hline 3 & 134 & 30.5 & Friends and boyfriends \\
\hline 4 & 123 & 28 & Death of family members \\
\hline
\end{tabular}

Table 6. Cluster of adults' Most Recent Dreams.

\begin{tabular}{lccl}
\hline Cluster & No. & $\mathbf{\%}$ & Name \\
\hline 1 & 116 & 19.6 & Home confinement \\
\hline 2 & 146 & 24.7 & Nostalgia for happiness \\
\hline 3 & 80 & 13.5 & Bodily sensations \\
\hline 4 & 135 & 22.9 & Dream evaluation \\
\hline 5 & 114 & 19.3 & Compliance with health and safety norms
\end{tabular}


temporarily locked in the back, for some strange reason I remember releasing my dog after 3 days of isolation in the back, feeling a strong and realistic non-guilt.'

Cluster 2: Nostalgia for happiness, comprised of 146 e.c.u. [of a total of 591 (24.7\%)]. Specific vocabulary: happy, wake up, feeling, peaceful, happy, hospital, laugh, review, reality, day, beautiful, crazy, cry, miss, square, set, doctor, ours. Examples of e.c.u.: 'I was on vacation in Ischia. I come back and find both my parents waiting for me, happy to see me again after a long time. It was a beautiful bright day. It was hot, but it wasn 't a muggy day. I woke up very calm and happy to have seen my father.. at least in a dream.' 'I remember that I was somewhere outside and there was a boy with me, I don't remember who. I remember I was very happy. But something was about to happen, and they woke me up.'

Cluster 3: Bodily sensations, comprised of 80 e.c.u. [of a total of $591(13.5 \%)$ ]. Specific vocabulary: start, hear, bed, succeed, run, blood, lose, respond, close, play, partner, watch, notice, nose, swim, back, garden, quarrel, follow, old. Examples of e.c.u.: 'I look in the mirror and feel something strange in my mouth.' 'At one point my sister approaches me and touches me with her hand, and I feel a kind of energy that makes me take flight. I start flying until I reach a beach where I meet my mother and other people I don't remember. Once I set foot on the ground, I cannot fly again.' 'My mother comes and calls me and tells me to go to sleep. I get up, close up the balcony, and start to feel a strange sensation. I can't quite move and speak.' 'I can hug him tightly.'

Cluster 4: Dream evaluation, comprised of 135 e.c.u. [of a total of $591(22.9 \%)$ ]. Specific vocabulary: pleasant, familiar, party, remembrance, change, number, hangout, colors, large, unpleasant, theater, dear, scenery, play, gray, presence, communicate, class, people. Examples of e.c.u.: 'I don't exactly remember the content of the first part of the dream, but I clearly remember a strong element of anxiety and unpleasant feelings.' 'Something happened that I don't remember but the scenery changed.' 'There is a pleasant atmosphere.' 'This part of the dream is characterized by a strong anger that I remember as unpleasant.'

Cluster 5: Compliance with health and safety norms, comprised of 114 e.c.u. [of a total of 591 (19.3\%)]. Specific vocabulary: exit, respect, awake, car, bill, palace, start, distance, search, field, greet, leave, safety, you, balcony. Examples of e.c.u.: 'I meet my boyfriend's cousin, who is dedicating himself to cleaning the streets. While I'm suddenly in an armored car, he tries in every way to greet me without respecting the one-meter distance, looking out the car window.' 'It was as if I had done various errands that are not allowed by the current restrictive measures, and I had not thought about the matter at all. While I was leaving the building anyway, and I was in the entrance hall (glass, hotel or shopping center style), there were many people, and they were not respecting the safety distances.'

\section{Discussion}

Beyond collecting data from the Dream Questionnaire, this study also examined the MRDs reported by Italian adults and adolescents. All dreams were coded by three independent judges, thus providing a more reliable and complete picture of the extent to which specific themes can be observed in MRDs during the first wave of the COVID-19 pandemic.

Consistent with previous research on dreams (e.g., Nielsen et al., 2000; Schredl, 2002, 2010b; Schredl \& Reinhard, 2008; Settineri et al., 2019), as well as with recent studies on dreaming in the time of COVID-19 (e.g., Barrett, 2020; Iorio et al., 2020; Parrello et al., 2020; McKay \& DeCicco, 2020; Pesonen et al., 2020; Scarpelli et al., 2021; Schredl \& Bulkeley, 2020), women reported the longest dreams. According to literature findings (e.g., Georgi, Schredl, Henley-Einion, \& Blagrove, 2012; Maggiolini, Morelli, Falotico, \& Montali, 2016; Riva Crugnola et al., 2008; Schredl, 2010b; Schredl \& Lahl, 2010; Schredl \& Reinhard, 2008; Settineri et al., 2019), they also recalled dreams more often than men. Furthermore, women reported a significantly higher emotional intensity of their dreams, as well as higher negative emotions and a higher presence of sensory impressions in their MRDs. Taken together, these data confirm our Hypothesis 1.

Adolescent participants reported the shortest dreams, in addition to recalling their dreams more often than adults. Furthermore, a relationship to people affected by or who have died of COVID-19 influenced their general oneiric life, in terms of higher emotional intensity and a negative emotional tone to their dreams.

Finally, a relationship to people affected by or who have died of COVID-19 influenced their MRDs, in terms of lower positive emotions, higher negative emotions, and a higher presence of sensory impressions, by confirming our Hypothesis 1.

For adult participants, a relationship to people affected by COVID-19 resulted in recalling their dreams more often. Furthermore, adult participants reported significantly higher negative emotions and a higher presence of sensory impressions in their MRDs. Finally, a relationship to people affected by or who have died of COVID-19 influenced their MRDs, in terms of lower positive emotions and higher negative emotions. In trying to understand the higher impact that a relationship to a COVID-19 case or death had on adolescents' MRDs, we can hypothesize an effect related to the type of information and the perspective spread by mass media during the first wave of the COVID-19 pandemic. Indeed, scientists, politicians, and opinion leaders have tried to empower younger people by emphasizing that they may be one of the first sources of infection for their grandparents, who have been identified as individuals at high risk. However, the media's stance has very probably had the effect of putting undue pressure 
on adolescents, by focusing on the consequences of their actions (e.g., Bianco, 2020).

Furthermore, according to the transformative function of dreams and dreaming (Adams-Silvan \& Silvan, 1990; Sommantico, 2018), we can hypothesize that a relationship to people affected by or who have died of COVID19 could stimulate the need for a dreamwork that would manifest itself in elaboration of emotions and fantasies, as well as in greater emotional intensity (especially negative) in dreams. Furthermore, this data is in line with both the continuity hypothesis of dreaming and waking life (e.g., Barrett, 2001; Hartman \& Basile, 2003; Rosen et al., 1991; Schredl, 2006) as well as classical psychoanalytic thinking, according to which significant events in waking life can be associated with specific experiences of dreaming, especially dreamt emotions.

In line with previous investigations (e.g., Schredl, 2002; Schredl \& Doll, 1998), emotions in dreams (especially positive ones) are underestimated by judges, in comparison to dreamers' self-ratings. This may be due to the fact that the judges took into account the presence of words that explicitly name emotions. Despite this difference, the correlations coefficients between the judges' ratings and the dreamers' self-ratings remain statistically significant.

The quali-quantitative analysis of the MRDs has also added important data. Textual analysis highlighted recurring themes in the MRDs, thus confirming our Hypothesis 2, as well as a strong continuity with waking experience. In fact, both adolescents and adults dreamt of various aspects of the home confinement imposed by the pandemic: the former with reference to life seen from the balcony, therefore with a sense of exclusion (cluster 1 adolescents); the latter with reference to escape from external danger (cluster 1 adults). Significant differences then emerge. In adolescents' dreams, the following appear: school (cluster 2), which has become a dangerous place, and which now crosses over into the home through distance learning; friends and boyfriends (cluster 3 ) in a situation of quarrel and betrayal, perhaps because there is a fear that distance will ruin relationships, but also because of possible misunderstandings or conflicts with friends or partners related to the effects of telecommunication; and the death of family members (cluster 4), probably due to information given by mass media on the danger to older people. Instead, in adults' dreams the following appear: nostalgia for the happiness of the past (cluster 2, the largest of the 5); references to bodily sensations (cluster 3), perhaps because the body is forced to endure various deprivations during quarantine, while also being scrutinized for symptoms; concern for compliance with health and safety norms (cluster 5), which have become pervasive in daily life. Finally, adults do not limit themselves to describing the dream, but often also add dream evaluations and post-hoc reflections (cluster 4).
Taken together, our results can be interpreted in light of the continuity hypothesis of dreaming, especially as applied to traumatic and/or catastrophic events (e.g., Barrett, 2001; Barrett, 2020; Iorio et al., 2020; Parrello et al., 2020; Hartman \& Basile, 2003; McKay \& DeCicco, 2020; Pesonen et al., 2020; Rosen et al., 1991; Scarpelli et al., 2021; Schredl, 2006; Schredl \& Bulkeley, 2020). Indeed, besides dreaming of waking life emotions (i.e., fear that distance will ruin relationships or fear of death of loved ones), people could have been dreamed of events that happened or events that they feared would happen (e.g., Revonsuo, 2000). These data indicate that the dreams of people living under quarantine-isolation measures related to the COVID-19 pandemic are characterized by strong negative emotional intensity, strong emotional tone, and the presence of sensory impressions.

It is clear that age has its own impact: the content of adolescents' dreams mainly concerns relational life: that is, family, school, friends and girl/boyfriends, while the content of adults' dreams is more about the Self, as threatened by dangers and restrictions. These data reflect the stated importance of peer relationships in adolescence, as well as the importance of in-person contact with classmates, friends, and teachers in this phase of the lifespan (e.g., Brown \& Larson, 2009; Roach, 2018). Indeed, due to the nationwide school closures, as well as to the interruption of every relationship outside the family and the prohibition of outdoor activities, the adolescent population can be considered particularly at risk (e.g., Cui, Li, \& Zheng, 2020; Kapetanovic, Gurdal, Ander, \& Sorbring, 2021; Luijten et al., 2021).

\section{Strengths and limitations}

In accordance with the recommendations of Schredl (2010a), the first strength of the present study is the use of both valid and reliable self-rated and judged dream content scales. In particular, regarding the rating scales utilized, the interrater reliability coefficients are high, as well as the confidence levels and the effect sizes (e.g., Hoffman, 2013).

The first general limitation is related to sampling strategy. Indeed, convenience sampling, such as snowball sampling, implies specific possible biases, such as volunteers' bias (related to the special characteristics of individuals who voluntarily participate in a study) (e.g., Hoffman, 2013). Furthermore, our sample was not balanced with respect to gender, and future research should try to work with more gender-balanced samples. Finally, another limitation relates to the lack of data on participants' oneiric lives prior to the onset of the COVID-19 pandemic, thus preventing comparisons.

In sum, previous limitations and the cross-sectional study design also limit the conclusions that can be drawn, especially regarding generalizability. 


\section{Conclusions}

The present study was conducted during the first wave of the COVID-19 pandemic in Italy, when every day mass media communicated the increasing numbers of the sick and dead, and continually reminded audiences, especially younger people, of the obligation to practice social distancing and isolation. Furthermore, in accordance with the continuity hypothesis of dreaming and with psychoanalytic thinking, our results show how a traumatic event, such as the COVID-19 pandemic, can appear in dreams both directly, through realistic dreams and explicit references to the virus, as well as indirectly and symbolically.

The contents of the dreams also show that subjects feel threatened in different ways by the COVID-19 pandemic based on their age.

In sum, this study demonstrates that the integration of clinical and experimental perspectives, which include both qualitative and quantitative analyses, when combined with different theoretical approaches, such as a psychoanalytic framework and the continuity hypothesis, contributes to a more accurate and comprehensive analysis of dreaming.

\section{References}

Adams-Silvan, A., \& Silvan, M. (1990). "A dream is the fulfillment of a wish": Traumatic dream, repetition compulsion, and the pleasure principle. The International Journal of Psychoanalysis, 71(3), 513-522.

Barrett, D. (2001). Trauma and Dreams. Harvard University Press.

Barrett, D. (2020). Dreams about COVID-19 versus normative dreams: Trends by gender. Dreaming, 30(3), 216-221. doi: 10.1037/drm0000149.

Benke, C., Autenrieth, L. K., Asselmann, E., \& Pané-Farré, C. A. (2020). Lockdown, quarantine measures, and social distancing: Associations with depression, anxiety and distress at the beginning of the COVID-19 pandemic among adults from Germany. Psychiatry Research, 293, 113462. doi: 10.1016/j.psychres.2020.113462.

Bianco, M. L. (2020). COVID-19. Perché la sociologia può essere utile anche di fronte a un'epidemia: storia di una scoperta [Because sociology can also be useful in the face of an epidemic: the story of a discovery]. Cambio. Rivista sulle trasformazioni sociali, First Online $1^{\text {st }}$ June. doi: 10.13128/cambio-8684.

Bradshaw, S., Lafrenière, A., Amini, R., Lortie-Lussier, M., \& De Koninck, J. (2016). Threats in dreams, emotions and the severity of threatening experiences in waking. International Journal of Dream Research, 9(2), 102-109. doi: 10.11588/ ijodr.2016.2.27214.

Brown, B. B., \& Larson, J. (2009). Peer relationships in adolescence. In R. M. Lerner \& L. Steinberg (Eds.), Handbook of adolescent psychology: Contextual influences on adolescent development (pp. 74-103). New York, NY: John Wiley \& Sons.

Casagrande, M., Favieri, F., Tambelli, R., \& Forte, G. (2020). The enemy who sealed the world: effects quarantine due to the COVID-19 on sleep quality, anxiety, and psychological distress in the Italian population. Sleep Medicine, 75, 12-20. doi: 10.1016/j.sleep.2020.05.011.

Cellini, N., Canale, N., Mioni, G., \& Costa, S. (2020). Changes in sleep pattern, sense of time and digital media use during COVID-19 lockdown in Italy. Journal of Sleep Research, 29(4), 13074. doi: 10.1111/jsr.13074.

Cui, Y., Li, Y., \& Zheng, Y. (2020). Mental health services for children in China during the COVID-19 pandemic: results of an expert-based national survey among child and adolescent psychiatric hospitals. European Child \& Adolescent Psychiatry, First Online 11 May. doi: 10.1007/s00787-02001548-x.

Davidson, J., \& Lynch, S. (2012). Thematic, literal, and associative dream imagery following a high-impact event. Dreaming, 22(1), 58-69. doi: 10.1037/a0026273.

Domhoff, G. W. (1996). Finding Meanings in Dreams. A Quantitative Approach. Berlin: Springer.

Domhoff, G. W. (2003). The Scientific Study of Dreams: Neural Networks, Cognitive Development, and Content Analysis. American Psychological Association.

Faustino, B., Branco Vasco, A., Delgado, J., Farinha-Fernandes, A., \& Guerreiro, J. C. (2020). Exploring the impacts of COVID-19 related social distancing on loneliness, psychological needs and symptomatology. Research in Psychotherapy: Psychopathology, Process and Outcome, 23(3), 222-230. doi: 10.4081/ripppo.2020.492.

Franceschini, C., Musetti, A., Zenesini C., Palagini, L., Scarpelli, S., Pelosi A., ... Castelnuovo, G. (2020). Poor sleep quality and its consequences on mental health during COVID-19. Frontiers in Psychology, 11, 574475. doi: 10.3389/ fpsyg.2020.574475.

Freud, S. (1900). The interpretation of dreams. In J. Strachey (Ed. and Trans.), The Standard Edition of the Complete Psychological Works of Sigmund Freud (Vols. 4 and 5). London: Hogarth Press.

Freud, S. (1915-17). Introductory lessons on psycho-analysis. In J. Strachey (Ed. and Trans.), The Standard Edition of the Complete Psychological Works of Sigmund Freud (Vol. 15). London: Hogarth Press.

Georgi, M., Schredl, M., Henley-Einion, J., \& Blagrove, M. (2012). Gender differences in dreaming in childhood and adolescence: The UK Library study. International Journal of Dream Research, 5, 125-129. doi: 10.11588/ijodr. 2012.2.9433.

Gorgoni, M., Scarpelli, S., Alfonsi, V., Annarumma, L., Cordone, S., Stravolo, S., \& De Gennaro, L. (2021). Pandemic Dreams: quantitative and qualitative features of the oneiric activity during the lockdown due to COVID-19 in Italy. Sleep Medicine, First Online 8 February. doi: 10.1016/ j.sleep.2021.02.006.

Gullo, S., Misici, I., Teti, A., Liuzzi, M., \& Chiara, E. (2020). Going through the lockdown: a longitudinal study on the psychological consequences of the coronavirus pandemic. Research in Psychotherapy: Psychopathology, Process and Outcome, 23(3), 211-221. doi: 10.4081/ripppo.2020.494.

Hall, C. S., \& Van de Castle, R. (1966). The Content Analysis of Dreams. Appleton-Century-Crofts.

Hartmann, E. (2011). The Nature and Function of Dreaming. Oxford: Oxford University Press.

Hartman, E., \& Basile, R. (2003). Dream imagery becomes more intense after 9/11/01. Dreaming, 13(2), 61-66. doi: 10.1023/A:1023398924124. 
Hewson, C., Vogel, C., \& Laurent, D. (Eds.) (2016). Internet Research Methods (2nd ed.). Newcastle: Sage.

Hoffman, C. (2013). Research articles in Dreaming: A review of the first 20 years. Dreaming, 23(3), 216-231. doi: $10.1037 / \mathrm{a} 0032905$.

Huang, Y., \& Zhao, N. (2020). Generalized anxiety disorder, depressive symptoms and sleep quality during COVID-19 epidemic in China: a web-based cross-sectional survey. Psychiatry Research, 288, 112954. doi: 10.1101/2020. 02.19.20025395.

Kapetanovic, S., Gurdal, S., Ander, B., \& Sorbring, E. (2021). Reported Changes in Adolescent Psychosocial Functioning during the COVID-19 Outbreak. Adolescents, 1, 10-20. doi: 10.3390/adolescents 1010002

Knight, Z. G. (2020). Living under lockdown in the shadow of the COVID-19 pandemic in South Africa: anxious voices from the unplanned shift to online therapy. Research in Psychotherapy: Psychopathology, Process and Outcome, 23(3), 202-210. doi: 10.4081/ripppo.2020.487.

IBM Corp. (2019). IBM SPSS Statistics for Windows, Version 26.0. IBM Corp.

Iorio, I., Sommantico, M., \& Parrello, S. (2020). Dreaming in the time of Covid-19: A quali-quantitative Italian study. Dreaming, 30, 199-215. doi: 10.1037/drm0000142.

Lancia, F. (2004). Strumenti per l'analisi dei testi [Tools for text analysis]. Milano: FrancoAngeli.

Lebow, J.L. (2020). Family in the Age of COVID-19. Family Process, First Online May 15. doi: 10.1111/famp.12543.

Luijten, M.A.J., van Muilekom, M.M., Teela, L., Polderman, T. J. C., Terwee, C. B., Zijlmans, J. ... Haverman, L. (2021). The impact of lockdown during the COVID-19 pandemic on mental and social health of children and adolescents. Quality of Life Research, First Online May 15. doi: 10.1007/s11136-021-02861-x.

Maggiolini, A., Morelli, M., Falotico, E., \& Montali, L. (2016). Dream contents of early adolescents, adolescents, and young adults: A cluster analysis with T-LAB. Dreaming, 26(3), 221-237. doi: 10.1037/drm0000027.

Mathes, J., \& Schredl, M. (2016). Threats in dreams: Are they related to waking-life? International Journal of Dream Research, 9(1), 58-66. doi: 10.11588/ijodr.2016.1.27499.

Mazza, C., Ricci, E., Biondi, S., Colasanti, M., Ferracuti, S., Napoli, C., \& Roma, P. (2020). A nationwide survey of psychological distress among Italian people during the COVID19 pandemic: Immediate psychological responses and associated factors. International Journal of Environmental Research and Public Health, 17(9), 3165. doi: 10.3390/ ijerph17093165.

McKay, C., \& DeCicco, T.L. (2020). Pandemic Dreaming: The Effect of COVID-19 on Dream Imagery, a Pilot Study. Dreaming, 30(3), 222-234. doi: 10.1037/drm0000148.

Nielsen, T.A., Leberge, L., Paquet, J., Tremblay, R.E., Vitaro, F., \& Montplaisir, J. (2000). Development of disturbing dreams during adolescence and their relation to anxiety symptoms. Sleep, 23(6), 727-736. doi: 10.1093/ sleep/23.6.1.

Parola, A., Rossi, A., Tessitore, F., Troisi, G., \& Mannarini, S. (2020). Mental Health Through the COVID-19 Quarantine: A Growth Curve Analysis on Italian Young Adults. Frontiers in Psychology, 11, 567484. doi: 10.3389/fpsyg.2 020.567484 .

Parrello, S., Sommantico, M., Lacatena, M., \& Iorio, I. (2020). Adolescents' dreams under Covid-19 isolation. International
Journal of Dream Research, 14, 10-20. doi: 10.11588/ijodr. 2021.1.73858.

Pesonen, A., Lipsanen, J., Halonen, R., Elovainio, M., Sandman, N., Mäkelä, J., ... Kuula, L. (2020). Pandemic Dreams: Network Analysis of Dream Content During the COVID-19 Lockdown. Frontiers in Psychology, 11, 573961. doi: 10.3389/fpsyg.2020.573961.

Prime, H., Wade, M., \& Browne, D. T. (2020). Risk and Resilience in Family Well-Being During the COVID-19 Pandemic. American Psychologist, 75(5), 631-643. doi: 10.1037/amp0000660.

Revonsuo, A. (2000). The reinterpretation of dreams: an evolutionary hypothesis of the function of dreaming. Behavioral and Brain Sciences, 23(6), 877-901. doi: 10.1017/ s0140525x00004015.

Riva Crugnola, C., Maggiolini, A., Caprin, C., De Martini, C., \& Giudici, F. (2008). Dream content of 10- to 11-year-old preadolescent boys and girls. Dreaming, 18(3), 201-216. doi: $10.1037 / \mathrm{a} 0013379$.

Roach, A. (2018). Supportive Peer Relationships and Mental Health in Adolescence: An Integrative Review. Issues in Mental Health Nursing, 39(9), 723-737. doi: 10.1080/ 01612840.2018.1496498.

Rosen, J., Reynolds, C.F., Yeager, A.L., Houck, P.R., \& Hurwitz, L.F. (1991). Sleep disturbances in survivors of the Nazi Holocaust. American Journal of Psychiatry, 148(1), 62-66. doi: 10.1176/ajp.148.1.62.

Rossi, R., Socci, V., Talevi, D., Mensi, S., Niolu, C., Pacitti, F., ... Di Lorenzo, G, (2020). COVID-19 Pandemic and Lockdown Measures Impact on Mental Health Among the General Population in Italy. Frontiers in Psychiatry, 11, 790. doi: 10.3389/fpsyt.2020.00790.

Scarpelli, S. Alfonsi, V., Mangiaruga, A., Musetti, A., Quattropani, M. C., Lenzo, V. ... Franceschini, C. (2021). Pandemic nightmares: Effects on dream activity of the COVID-19 lockdown in Italy. Journal of Sleep Research, First Online 6 February. doi: 10.1111/jsr.13300.

Schredl, M. (2002). Questionnaire and diaries as research instruments in dream research: Methodological issues. Dreaming, 12(1), 17-26. doi: 10.1023/A:1013890421674.

Schredl, M. (2006). War-related dream themes in Germany from 1956 to 2000. Political Psychology, 27(2), 299-307. doi: 10.1111/j.1467-9221.2006.00008.x.

Schredl, M. (2010a). Dream content analysis: Basic principles. International Journal of Dream Research, 3(1), 65-73. doi: 10.11588/ijodr.2010.1.474.

Schredl, M. (2010b). Explaining the gender difference in dream recall frequency. Dreaming, 20(2), 96-106. doi: 10.1037/ a0019392.

Schredl, M. \& Bulkeley, K. (2020). Dreaming and the COVID19 pandemic: A survey in a U.S. sample. Dreaming, 30(3), 189-198. doi: 10.1037/drm0000146.

Schredl, M., \& Doll, E. (1998). Emotions in diary dreams. Consciousness and Cognition, 7(4), 634-646. doi: 10.1006/ccog. 1998.0356.

Schredl, M., \& Lahl, O., (2010). Gender, sex role orientation, and dream recall frequency. Dreaming, 20(3), 19-24. doi: 10.1037/a0018578.

Schredl, M., \& Reinhard, I. (2008). Gender differences in dream recall: A meta-analysis. Journal of Sleep Research, 17(2), 125-131. doi: 10.1111/j.1365-2869.2008.00626.x.

Settineri, S., Frisone, F., Alibrandi, A., \& Merlo, E.M. (2019). Italian adaptation of the Mannheim Dream Questionnaire 
(MADRE): Age, gender and dream recall effects. International Journal of Dream Research, 12(1), 119-129. doi: 10.11588/ijodr.2019.1.59328.

Sher, L. (2020). COVID-19, anxiety, sleep disturbances and suicide. Sleep Medicine, 70, 124. doi: 10.1016/j.sleep. 2020.04.019.

Sommantico, M. (2010). La Ciénaga. Ou le malaise dans la famille comme révélateur du Malaise dans la culture. Cahiers de Psychologie Clinique, 34, 205-217. doi: $10.3917 / \mathrm{cpc} .034 .0203$.

Sommantico, M. (2016). A couple's unconscious communication: dreams. British Journal of Psychotherapy, 32, 456-474. doi: 10.1111/bjp.12251.

Sommantico, M. (2018). La fonction transformatrice du rêve [The transformative function of the dream]. Revue française de psychanalyse, 82, 1475-1480. doi: 10.3917/rfp.825.1475.

Sommantico, M., De Rosa, B., \& Parrello, S. (2017). Counselling University Students: A Psychoanalytic Approach of the Single Case Report. Mediterranean Journal of Clinical Psychology, 5. doi: 10.6092/2282-1619/2017.5.1354.

Sommantico, M., Donizzetti, A. R., De Rosa B., Parrello S., \& Osorio Guzmán, M. (2015). L'invarianza per età nella vali- dazione italiana dell'Aggression Questionnaire (AQ) di Buss e Perry. Psicologia della salute, 3, 111-125. doi: 10.3280/PDS2015-003006.

Xiao, H., Zhang, Y., \& Kong, D. (2020). Social capital and sleep quality in individuals who self-Isolated for 14 days during the Coronavirus Disease 2019 (COVID-19) outbreak in January 2020 in China. Medical Science Monitor, 26, 923921. doi: 10.12659/MSM.923921.

Wang, C., Zhou, J., \& Zong, C. (2020). Two cases report of epidemic stress disorder to novel coronavirus pneumonia. Asian Journal of Psychiatry, 51, 102070. doi: 10.1016/j.ajp.2020. 102070.

Zandifar, A., \& Badrfam, R. (2020). Iranian mental health during the COVID-19 epidemic. Asian Journal of Psychiatry, 51, 101990. doi: 10.1016/j.ajp.2020.101990.

Zurlo, M. C., Cattaneo della Volta, M. F., \& Vallone, F. (2020). COVID-19 Student Stress Questionnaire: Development and Validation of a Questionnaire to Evaluate Students' Stressors Related to the Coronavirus Pandemic Lockdown. Frontiers in Psychology, 11, 576758. doi: 10.3389/fpsyg.2020. 576758. 